\title{
REVIEW ARTICLE ON PULSATILE DRUG DELIVERY SYSTEM
}

\author{
VENKATASWAMY R*, LAVANYA NALLAGUNTLA
}

Department of Pharmaceutics, The Oxford College of Pharmacy, Bengaluru, Karnataka, India. Email: venkataswamygowda123@gmail.com Received: 17 March 2021, Revised and Accepted: 19 May 2021

\begin{abstract}
Pulsatile drug delivery systems (PDDS) are acquiring a lot of interest as they deliver the medication at the right place at the right time and in the right amount, subsequently giving spatial and transient delivery and increasing patient consistency. These systems are designed by the circadian rhythm of the body. The primary reasoning for the utilization of pulsatile arrival of the medications is the place where a consistent medication release is not desired. A pulse must be planned so that a complete and rapid medication release is accomplished after the lag time. A different system such as capsular system, osmotic system, single-and multiple unit system dependent on the utilization of soluble or erodible polymer coating, and the utilization of rupturable films has been managed in the article. It sums up the most recent technology development, formulation parameter, and delivery profiles of this system. PDDS is helpful for the medications having chronopharmacological conduct where night-time dosing is required, such as anti-arrhythmic, anti-ulcerative, and anti-asthmatic, and so on The momentum survey article talked about the explanations behind the advancement of the PDDS, benefits, limitation, mechanism of medication release, need for pulsatile drug delivery, a disease that requires pulsatile technology, classification, and future parts of PDDS.
\end{abstract}

Keywords: Pulsatile drug delivery system, Press-coated, Methodologies, Marketed technologies, Biological rhythm.

(c) 2021 The Authors. Published by Innovare Academic Sciences Pvt Ltd. This is an open access article under the CC BY license (http://creativecommons.org/ licenses/by/4.0/) DOI: http://dx.doi.org/10.22159/ajpcr.2021v14i6.41476. Journal homepage: https://innovareacademics.in/journals/index.php/ajpcr

\section{INTRODUCTION}

Oral drug delivery is that the largest segment of the entire drug delivery market. It is the foremost preferred route for drug administration. The oral controlled-release systems show a typical pattern of drug release in which the drug concentration is maintained in the therapeutic window for a prolonged period time thereby ensuring sustained therapeutic action. There are certain conditions for which such a delivery design is not appropriate that request arrival of medication after a lag time. In other words, they require a pulsatile drug delivery system (PDDS). PDDSs are designed by the biological rhythm of the body [1,2] Modified release dosage forms have acquired importance in the current pharmaceutical R and D business. Such systems offer control over the release pattern of drugs and provide better control over drug regimens [3]. Conventionally, drugs are released in an instantaneous or extended fashion. A pulsatile drug release, where the drug is released rapidly after a well-defined lag-time, could be advantageous for many drugs or therapies [4].

A PDDS is characterized as the quick and transient release of a specific amount of drug molecule within a short period immediately after a predetermined off-release period, that is, lag time. There are numerous circumstances where the medication should have been delivered after a lag time at the particular site. These situations, therefore, compel designing a delayed fast release system such as pulsatile release systems [5]. A pulse must be produced so that a complete and fast medication release is accomplished after the lag time chance to coordinate with the body's circadian rhythm. These systems are characterized by two release phases. A first phase during which little drug is released, followed by a second phase, during which the drug is released completely within a short period after a lag time. Most PDDSs are repository gadgets coated by a barrier polymeric coating. The coating prevents drug release from the core until the polymeric shell is completely dissolved, eroded, or ruptured during/after a certain lag time. After this, the drug is released rapidly from the inner reservoir core [6]. Pulsatile release tablet formulation generally consists of a rapid release core tablet encased in a barrier layer either formed by presscoating or liquid coating or a combination of both [7]. Pulsatile drug delivery is hence one device that gives strong promises of benefit to patients experiencing a constant condition such as joint inflammation, asthma, ulcer, hypertension, by delivering the medicine at the correct time, an ideal spot, and in the right amounts [8]. PDDSs have a peculiar mechanism of delivering the drug rapidly and completely after a lag time, that is, a period of no drug release. Such a release pattern is known as pulsatile release [9,10] (Fig. 1).

Schematic representation of different drug delivery systems was (A) sigmoidal release after the lag time, (B) delayed-release after the lag time, (C) sustained-release, (D) extended-release without lag time.

People show endogenous circadian rhythms that are directed by the expert circadian clock of the body, the suprachiasmatic core. Chronopharmacotherapy of infections (bronchial asthma, myocardial localized necrosis, angina pectoris, rheumatic illness, ulcer, and hypertension) that show circadian rhythms in their pathophysiology and treatment of such sicknesses require pulsatile drug conveyance frameworks, by which medication is delivered quickly and totally as a heartbeat after a slack time [11-13].

Numerous different conditions request pulsatile discharge, in the same way as other body works that follow circadian rhythms, for example, emission of chemicals (including follicle-stimulating hormone, luteinizing hormone [LH], LH-releasing hormone, estrogen, and progesterone), corrosive emission in the stomach, gastric exhausting, and gastrointestinal (GI) blood bonding [14]. Medications that produce natural resilience request a framework that will forestall their consistent presence at the biophase, as this will in general diminish their helpful impact. The slack time is fundamental for drugs that go through corruption in gastric acidic medium (e.g., peptide drug) and bother the gastric mucosa or prompt sickness and regurgitating. Focusing on medication to a distal organ of the GI tract (GIT), like the colon, necessitates that the delivery is forestalled in the $66 \%$ segment of the GIT. Medications ( $\beta$-blockers or $\beta$-estradiol) that go through the primary pass digestion, bringing about decreased bioavailability, modified consistent state levels of medication and metabolite, and potential food-drug connection, require deferred delivered to the degree conceivable [15-17]. 


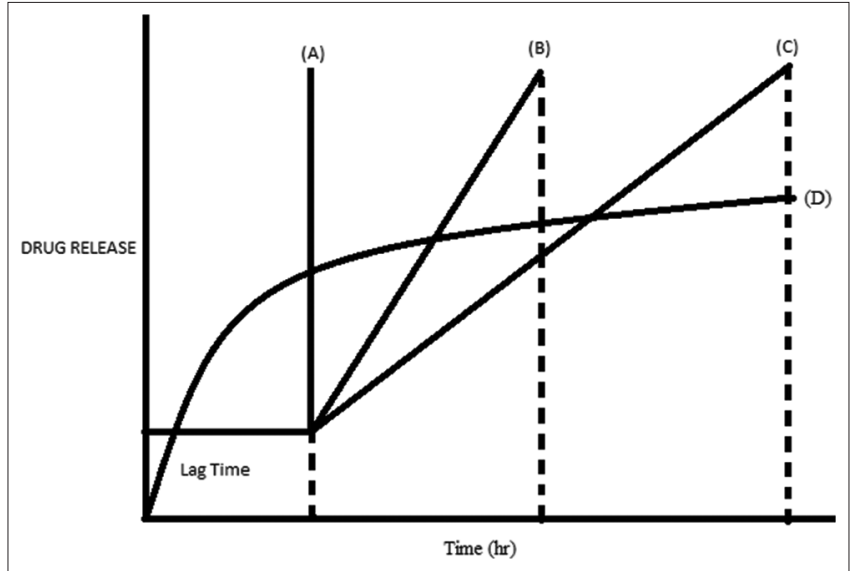

Fig. 1: Drug release profiles

To present the idea of chronotherapeutics, it is imperative to characterize the accompanying ideas:

\section{Chronobiology}

Chronobiology is the science worried about the natural system of the diseases as per a period structure. "Chrono" relates to time and "science" relates to the study, or science, of life.

\section{Chronopharmacology}

Chronopharmacology is the science worried about the varieties in the pharmacological activities of different medications throughout some times of the day [18].

\section{Chronopharmacokinetics}

Chronopharmacokinetics includes the investigation of transient changes in drug absorption, distribution, metabolism, and excretion. Pharmacokinetic parameters, which are traditionally viewed as consistent on time, are impacted by various two physiological capacities showing circadian beat. Circadian changes in gastric corrosive discharge, GI motility, GI bloodstream, drug-protein restricting, liver catalyst action, renal bloodstream, and urinary $\mathrm{pH}$ can assume a part in the time-dependent variety of medication plasma concentration.

\section{Chronotherapy}

Coordination of biological rhythms and clinical treatment is called chronotherapy $[18,19]$

\section{Chronotherapeutics}

Chronotherapeutics is the order worried about the conveyance of medications as per the inalienable exercises of a disease over a specific period. It is turning out to be progressively more obvious that the particular time that patients take their drug might be much more critical than was perceived in the past $[18,20]$.

\section{BIOLOGICAL RHYTHMS}

\section{Ultradian rhythms}

Oscillations of shorter duration are termed as Ultradian Rhythms (more than one cycle for each 24 h). E.g., 90 min rest cycle.

\section{Infradian rhythms}

Oscillations that are longer than $24 \mathrm{~h}$ are named Infradian Rhythms (short of one cycle for each $24 \mathrm{~h}$ ), for example, Monthly Menstruation.

\section{Circadian rhythms}

Circadian rhythms are self-maintaining, endogenous oscillations that happen with a periodicity of around $24 \mathrm{~h}$. Strangely, the term circadian is gotten from the Latin around which signifies "about" and dies which can be characterized as "a day." Regularly, circadian rhythms are synchronized by interior biologic clocks identified with the rest wake cycle [21] (Fig. 2).

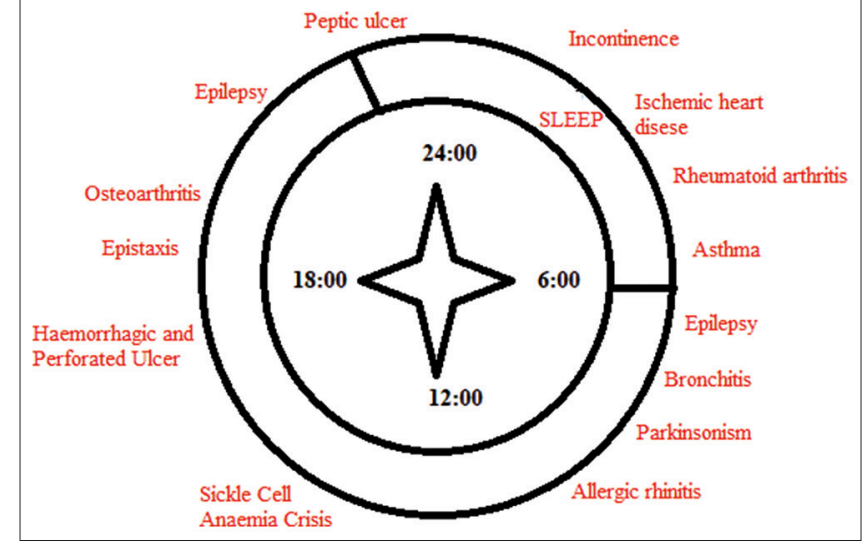

Fig. 2: Cycle for circadian rhythm

\section{BENEFIT OF PDDS}

There are numerous benefits of the pulsatile measurement structure over regular dose structure.

1. Increase the absorption and bioavailability than conventional immediate release or sustained release drugs because of their capacity to deliver the medication in a burst way, at the objective site of assimilation.

2. Site targeting permits the delivery of poorly bioavailable medications that would get destroyed in a higher GIT climate, for example, (peptide and protein molecule).

3. Lessens the dose of the medication without decreasing the therapeutic effect.

4. Decreasing the adverse effect.

5. Decreases drug interaction because of the lower cytochrome P450isoenzymes.

6. Decreases food impact (change happening in bioavailability of medication when given with food).

7. Improved patients' consistency.

8. Chronotherapy modified delayed discharge gives an ideal treatment of the disease.

9. Pulse discharge allows various dosing in a single dosage form

10. Broadened daytime or night-time activity [22].

11. Lower day-by-day expenses to the patient because fewer dosage units are needed by the patient in treatment.

12. Medication adjusts to suit circadian rhythms of the body.

13. Shields mucosa from aggravating medications.

14. Medication loss is prevented by the first-pass metabolism.

15. No danger of dose dumping.

16. Because of its ability to deliver the medication in a burst way, it will increase absorption and bioavailability at the target site of absorption Avoid biological tolerance.

17. Expectable, reproducible, and little gastric dwelling period.

18. Adaptability in drug delivery system designing [23-25].

19. They give constant medication levels at the site of activity and prevent the peak-valley changes [26].

\section{DRAWBACK OF PDDS}

1. Low drug loading capacity and fragmented arrival of the drug.

2. Greater expense of production.

3. A large number of process variables.

4. Absence of assembling reproducibility and viability [23].

\section{MECHANISM OF DRUG RELEASE FROM PDDS}

The mechanism of drug release from the PDDSs occurs in the following ways.

\section{Diffusion}

Water diffuses into the inside of the molecule. Particles interact with watery liquids in the GIT tract and resultant medication arrangements diffuse across the delivery coat to the outside. 


\section{Erosion}

Some coatings intended to dissolve steadily with time, bring about the arrival of the medication contained inside the molecule.

\section{Osmosis}

An osmotic pressing factor can be developed inside the inside of the molecule when water is permitted to enter in specific situations. The medication is constrained out of the molecule into the outside through the covering [27]

\section{NEED OF PULSATILE DRUG DELIVERY}

Pulsatile drug conveyance is fundamental when,

1. Body rhythm follows circadian rhythms.

2. Circadian rhythm is modified by the hormone-like rennin, aldosterone, cortisol, and so forth.

3. Rhythm variety is found in acid secretion in the stomach, gastric purging, and GI blood transfusion.

4. Diseases such as bronchial asthma, myocardial localized necrosis, angina pectoris, rheumatic infection, ulcer, and hypertension show time reliance.

5. Lag time is essential for the medications that go through degradation in gastric acidic medium.

6. Medications should be delivered to the distal part of GIT like a colon.

7. Medications undergo broad first-pass metabolism [23].

\section{DISEASE THAT REQUIRE PULSATILE TECHNOLOGY}

A few diseases are needed to be formulated as PDDS.

1. Asthma is a disease wherein a PDDS can be helpful. Circadian changes are found in typical lung function, which arrives at a depressed spot in the early morning hours.

2. On account of cardiovascular infections, a few capacities (e.g., BP, pulse, stroke volume, cardiac output, and blood stream) of the cardiovascular framework are dependent on circadian rhythms. It has been accounted for that more stuns and respiratory failures happen during the morning hours

3. Blood pressure is reported to be high toward the beginning of the day (morning) till late afternoon and afterward drops off during the night.

4. Platelet aggregability is increased and fibrinolytic movement is diminished in the morning, prompting a condition of relative hypercoagulability of the blood.

5. Circadian varieties of glucose and insulin in diabetes have been broadly examined and their clinical significance on account of insulin replacement in type 1 diabetes has been all around abused.

6. Different directions of circadian changes in lipid fraction in patients and ordinary subjects may add to modification in the rhythmicity of different digestion systems and the blood coagulation framework, subsequently prompting different inconveniences. A circadian rhythm happens during hepatic cholesterol synthesis.

7. Patients experiencing osteoarthritis are accounted for to have less pain in the first part of the day (morning) than night-time, while patients experiencing rheumatoid joint inflammation feel more pain toward the beginning of the day hours.

8. A large number of the elements of the GIT are dependent on circadian rhythms. Gastric corrosive discharge is most noteworthy around night-time, while gastric motility and gastric emptying are all slower around night-time. Since maximal corrosive discharge, peptic ulcer infection torment, and hole of gastric and duodenal ulcers are more normal around evening time, organization of medications at sleep time is more compelling as of now. Night-time organization diminishes corrosive emission all the more adequately as well as advances ulcer mending and decreases ulcer repeat. Sleep time $\mathrm{H} 2$ receptor barricade is one such routine [28].

\section{METHODOLOGIES FOR PULSATILE DRUG DELIVERY}

Methodologies for the PDDS can be broadly classified into three classes,
PDDS can be broadly classified into three classes;

I. Time controlled pulsatile drug delivery.

II. Stimuli induced pulsatile drug delivery.

III. Externally regulated pulsatile drug delivery.

Time controlled pulsatile drug delivery

A. Single unit pulsatile systems.

1. Capsule based systems

For example, Pulsincap system.

2. Capsular system based on Osmosis

a. "PORT" System

b. System based on expandable orifice.

c. Delivery by series of stops.

d. Pulsatile delivery by solubility modulation.

3. Pulsatile system with Erodible or soluble barrier coatings

a. The chronotropic system.

b. Time clock System.

c. Compressed tablets.

d. Multilayered Tablets.

4. Pulsatile system with a rupturable coating.

B. Multiparticulate/Multiple unit systems.

1. Pulsatic system with a rupturable coating. For example, Time-controlled Explosion system (TCES)

2. Osmotic based rupturable coating system. For example, Permeability controlled system.

3. Pulsatic delivery by a change in membrane permeability For example, Sigmoidal release system [29].

Stimuli-induced pulsatile drug delivery

A. Thermoresponsive pulsatile release.

B. Chemical stimuli-induced pulsatile release.

Externally regulated pulsatile drug delivery

A. Electro responsive pulsatile release.

B. Ultrasonically stimulated.

C. Magnetically induced pulsatile release

\section{Single unit pulsatile system}

Capsule based system

Single-unit systems are generally evolved in capsule structure. The lag time is controlled by a plug, which moves drove away by swelling or erosion, and the drug is delivered as a "pulse" from the insoluble capsule body [30]. The lag time can be controlled by the measurement and the position of the plug $[31,32]$

Polymers utilized for planning the hydrogel plug

1) Insoluble yet penetrable and swellable polymers (e.g., polymethacrylates)

2) Erodible compressed polymers

(e.g., hydroxypropyl methylcellulose [HPMC], polyvinyl liquor, and Polyethylene oxide)

3) Congealed melted polymers (e.g., saturated polyglycolide glycerides and glyceryl monooleate)

4) Enzymatically controlled erodible polymer (e.g., pectin) [33,34]. The preparation and in vitro release of the tetramethylpyrazine phosphate pulsincap capsule have been reported. It was set up through fixing the medication tablet and fillers inside an impermeable case body with an erodible attachment. To meet the chronotherapeutic prerequisites, an appropriate lag time can be accomplished by changing the substance of gel-forming polymers such as HPMC and the erodible fitting weight [35]

\section{Capsular system based on Osmosis}

"PORT"

The port system was developed by the Therapeutic framework research lab Ann Arbor, Michigan, USA, and consists of a capsule coated with a semipermeable layer. Inside the capsule was insoluble plug consist of an osmotically active agent and the drug formulation. At the point 
when this case intact with the dissolution fluid, the semipermeable film permitted the section of water, which made the pressing factor create and the insoluble fitting removed after a lag time. Such a framework was used to convey methylphenidate utilized in the treatment of consideration shortfall hyperactivity issue as the pulsatile port framework. This framework kept away from $2^{\text {nd }}$-time dosing, which was advantageous for younger children during the daytime.

\section{System based on expandable orifice}

To release the medication in liquid form, an osmotically determined capsular system was created in which the liquid medication is absorbed into highly porous particles, which discharge the medication through a hole of a semipermeable capsule supported by an expanding osmotic layer after the hindrance layer is dissolved [36].

\section{Delivery by series of stops}

This system is depicted for implantable capsules. The container contains medication and a water absorptive osmotic motor that is placed in compartments separated by a movable partition. The pulsatile delivery is achieved by a series of stops along with the inner wall of the capsule. These stops hinder the movement of the partition but are overcome in succession as the osmotic pressure rises above a threshold level [37].

\section{Pulsatile delivery by solubility modulation}

Such a system contains a solubility modulator for pulsed delivery of a variety of medications. The framework was exceptionally created for the delivery of salbutamol sulfate [38]. The composition contains the medication (salbutamol sulfate) and a modulating agent (sodium chloride). The amount of $\mathrm{NaCl}$ was with the end goal that it was not exactly the sum expected to keep up immersion in a liquid that enters the osmotic gadget. The pulsed delivery is depends on

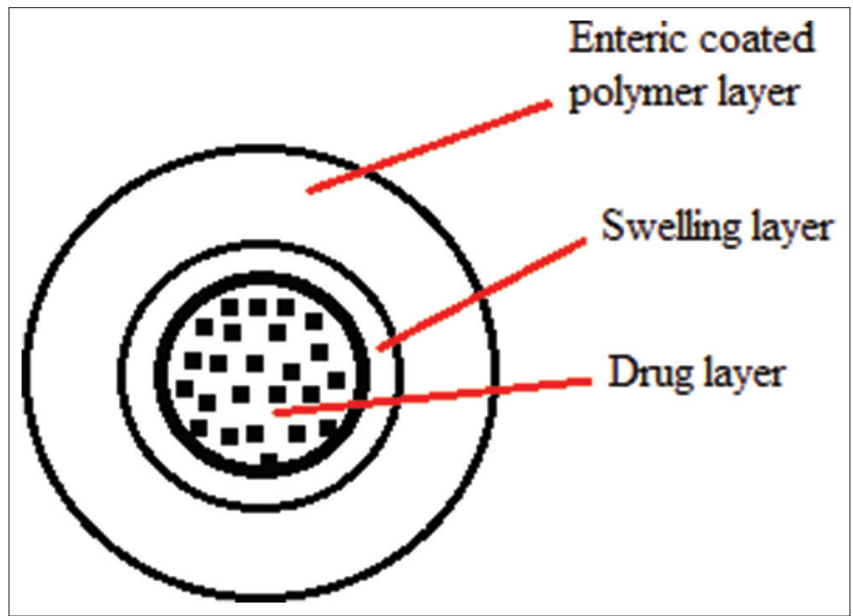

Fig. 3: The chronotropic system drug solubility. Salbutamol has a solubility of $275 \mathrm{mg} / \mathrm{ml}$ in water and $16 \mathrm{mg} / \mathrm{ml}$ in a soaked arrangement of $\mathrm{NaCl}$, while $\mathrm{NaCl}$ has a solubility of $321 \mathrm{mg} / \mathrm{ml}$ in water, and its saturation solubility is $320 \mathrm{mg} / \mathrm{ml}$.

Pulsatile system with erodable or soluble barrier coatings The greater part of the PDDS is reservoir devices coated with an obstruction layer. This obstruction erodes or breaks up after a particular lag period, and the medication is consequently released rapidly from the reservoir core. The lag time depends on the thickness of the covering layer.

\section{The Chronotropic system}

The Chronotropic ${ }^{\circledast}$ framework consists of a medication containing a core covered by hydrophilic swellable HPMC, which is responsible for a lag stage at the beginning of delivery. Moreover, through the utilization of an external gastric safe enteric film, the changeability in gastric purging emptying time can be overcome, and a colon-specific delivery can be acquired, depending on the general reproducibility of little intestinal travel time. The lag time is controlled by the thickness and the viscosity grade of HPMC. Both in vitro and in vivo lag time corresponds well with the applied amount of the hydrophilic retardant polymer. The framework is suitable for both tablets and containers [39] (Fig. 3).

\section{"Time clock" system}

The lag time could be controlled by changing the thickness of the film. After the lag time, that is, the time needed for rehydration, the core promptly delivers the medication. This framework has shown reproducible outcomes the result in vitro and in vivo. The impact of lowcalorie and unhealthy suppers on the slack time was examined utilizing gamma scintigraphy. The mean slack season of medication discharge was 345 and 333 min, respectively (Fig. 4).

\section{Compressed tablets}

Compression coating can include direct pressure of both the core and the coat, forestalling needs for a different coating process, and utilization of covering arrangements. The outer tablet of the compression-coated table provides the initial dose, quickly disintegrating in the stomach and the internal layer is planned with segments that are insoluble in gastric media however are delivered in the intestinal site. Materials, for example, hydrophilic cellulose derivatives can be utilized. Compression is simple on a research laboratory scale. The significant disadvantages of the strategy are that generally a lot of coating materials are required and it is hard to position the core effectively [40] (Fig. 5).

\section{Press-coated PDDSS}

1. Press-coated PDDS can be utilized to secure hygroscopic, lightsensitive, oxygen labile or acid-labile medications.

2. Press-coated PDDSs are moderately simple and cheap.

1. This system can include direct compression of both the core and the coat.

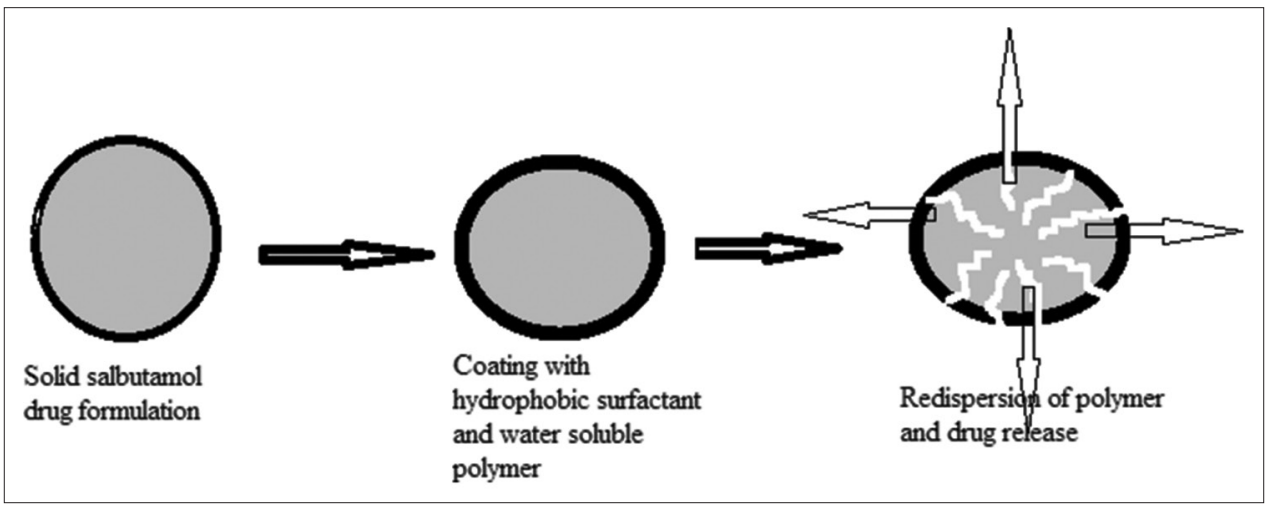

Fig. 4: 'Time clock' system 
2. Materials such as hydrophobic, hydrophilic can be utilized in presscovered PDDS.

3. A press-coated PDDS include compression which is simple on a research laboratory scale.

4. Press-coated pulsatile formulation release the drug after "lag time."

5. Press-coated pulsatile drug delivery formulation can be utilized to

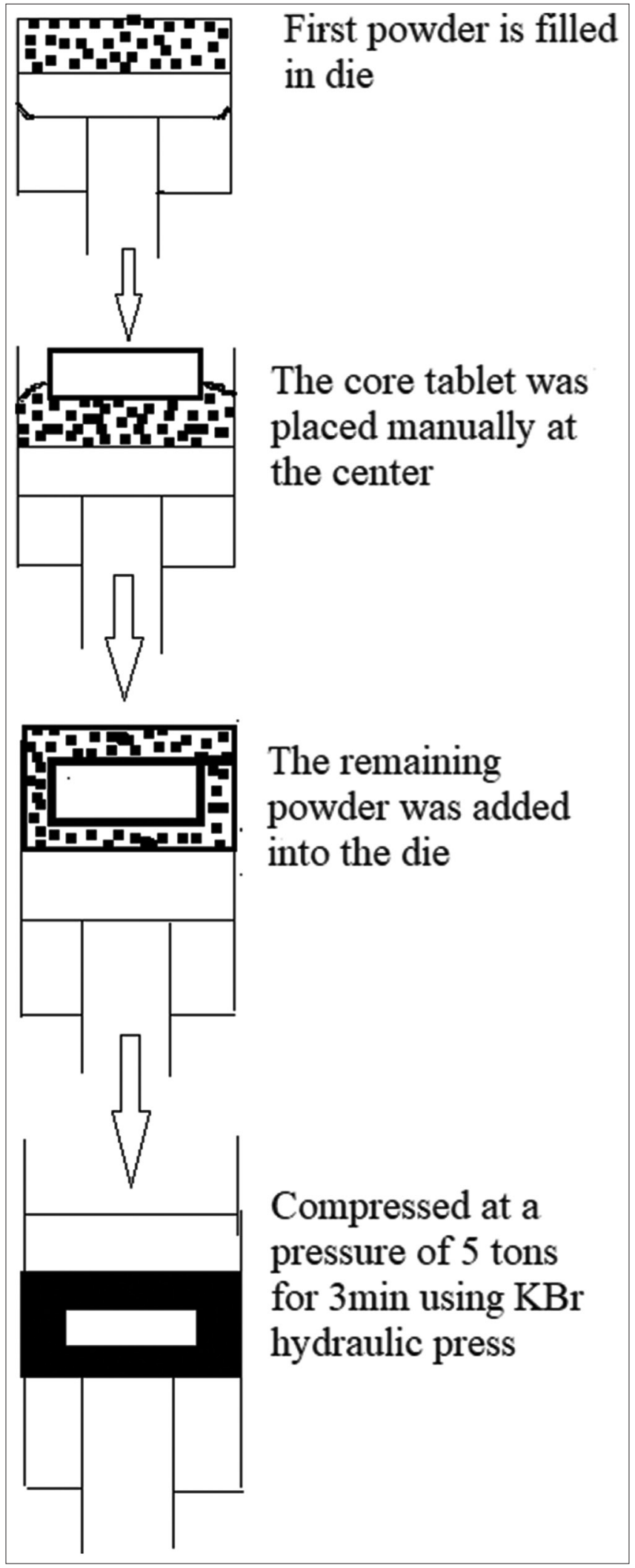

Fig. 5: press-coating technique separate medications from each other or to accomplish sustained delivery.

\section{Multi-layered tablets}

A delivery design with two pulses was gotten from a three-layered tablet containing two medication-containing layers separated by a medication-free gellable polymeric hindrance layer [41] (Fig. 6).

\section{Pulsatile system with a rupturable coating}

This system depends on the disintegration of the coating for the release of the medication. The pressing factor essential for the rupture of the coating can be accomplished by the effervescent excipients, swelling agent, or osmotic pressing factor. An effervescent combination of citrus acid and sodium bicarbonate was fused in a tablet core coated with ethyl cellulose. The carbon dioxide created after penetration of water into the core resulted in a pulsatile release of medication after the rupture of the coating. The delivery may rely on the mechanical properties of the coating layer [42].

\section{Multiparticulate/Multiple-unit system}

a. Pulsatile system based on rupturable coating

For example: TCES

This is a multiparticulate system in which the medication is coated on nonpareil sugar seeds followed by a swellable layer and an insoluble top layer [43] (Fig. 7).

b. Osmotic based rupturable coating system

This system depends on a combination of osmotic and swelling effects. The core containing the medication, a low mass density solid or potentially fluid lipid material (e.g., mineral oil), and a disintegrant were readied. This core was then covered with cellulose acetic acid derivation. Upon immersion in an aqueous medium, water penetrates the core displacing lipid material. After the exhaustion of lipid material, the inside pressure increments until basic pressure is reached, which brings about a break of coating [44].

\section{c. Pulsatile delivery by a change in membrane permeability}

The permeability and water take-up of acrylic polymers with quaternary ammonium gatherings can be affected by the presence of various counter-particles in the medium. A few conveyance frameworks dependent on this particle trade have been created. Eudragit RS 30D is accounted for to be a polymer of decision for this reason. It commonly contains an emphatically spellbound quaternary ammonium bunch in the polymer side chain, which is constantly joined by regrettable hydrochloride counter-particles. The ammonium bunch being hydrophilic works with the collaboration of the polymer with water, consequently changing its permeability and permitting water to saturate the dynamic core in a controlled way. This property is fundamental to accomplish a decisively characterized lag time [44].

Stimuli-induced pulsatile drug delivery

Stimuli-based medication delivery systems discharge the medication because of improvements that are initiated by the biological environment. The arrival of the medication in light of those frameworks results from improvements incited changes in the gels or in the micelles, which might

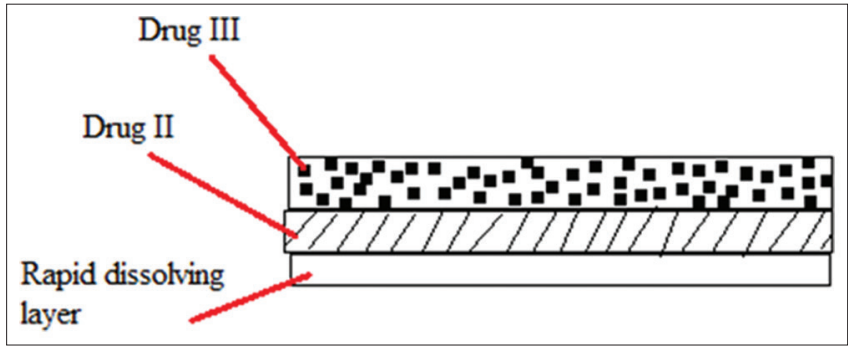

Fig. 6: Multi-layered tablets 


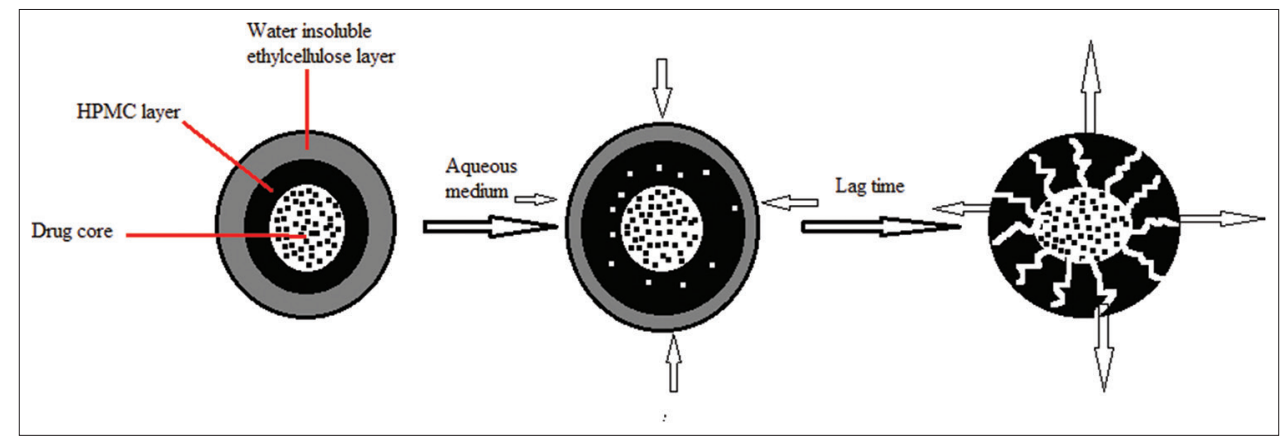

Fig. 7: Time-controlled explosion system

be swelling or erode because of the individual stimuli. In these systems, the medication is delivered after stimulation by any biological factor, similar to temperature, or some other chemical stimuli [45]. The systems of medication discharge incorporate the launch of the medication from the gel as the liquid eliminates syneresis, drug dissemination along a fixation angle, electrophoresis of charged medications toward an oppositely charged anode, and freedom of the entangled medication as the gel or micelle complex dissolves. There has been a lot of interest in the advancement of a boosts touchy delivery system that discharges remedial specialists within the sight of a particular chemical or protein. These systems are viewed as superb delivery applicants since they can be adjusted by the assignment to be accomplished.

They are additionally characterized into,

\section{Thermoresponsive pulsatile release}

Hydrogels that go through reversible volume changes because of temperature changes are known as thermosensitive gels. Thermosensitive hydrogels have been explored as conceivable medication conveyance transporters for improvements in responsive medication delivery. Hydrogels are cross-linked organizations of natural, manufactured, or semi-engineered polymers. These gels recoil at a progress temperature that is identified with the lower basic arrangement temperature of the straight polymer from which the gel is made. One of the regular qualities of temperature-sensitive polymers is the presence of hydrophobic gatherings, such as methyl, ethyl, and propyl gatherings. From the numerous temperature-delicate polymers, poly(N-isopropyl acrylamide) is presumably the most widely utilized. PINPA cross-connected gels have shown thermoresponsive, irregular expanding/deswelling stages, growing, for instance, at temperatures beneath $32^{\circ} \mathrm{C}$, and contracting over this temperature. Krezanoski et al. portray the utilization of the switched warm gelation (RTG) framework, comprising a polyol polymer, like Pluronic ${ }^{\circledR}$. Gels of this kind of polymer show low consistency at encompassing temperature and display a sharp expansion in thickness as the temperature rises. Yuk et al. created temperature-delicate medication conveyance frameworks using an admixture of poly (ethylene oxide)- poly (propylene oxide)- poly (ethylene oxide) triblock copolymer, and polyvinyl liquor (PVA) The pulsatile arrival of acetaminophen happened because of a pulsatile change in temperature somewhere in the range of $35^{\circ} \mathrm{C}$ and $40^{\circ} \mathrm{C}[46]$.

\section{Chemical stimuli-induced pulsatile release}

The development of a stimuli-sensitive system has been the most recent subject of interest. These systems release therapeutic agents in the presence of any biological factor similar to a catalyst, $\mathrm{pH}$, or some other substance improvements. One noticeable use of this innovation has been the advancement of a framework that can consequently deliver insulin in light of raised blood glucose levels [47]. Kazunori et al. built up a gel made out of PNIPAAm with phenylboronic corrosive moieties that showed a surprising change in the growth actuated by glucose. This sort of glycol-delicate gel may have potential utility in self-directed medication delivering systems just as in different applications, such as actuators, controllers, and partition frameworks with glycol sensitivity.
PH-subordinate system for glucose-stimulated medication conveyance depends on the oxidation response of glucose to gluconic corrosive, catalyzed by glucose oxidase, which can bring down PH to around 5.8 in a glucose-rich climate, like the circulatory system after a dinner. This response can be utilized to drive the expansion of a $\mathrm{pH}$-dependent film. A double layer system was shaped, with the primary film alluded to as the glucose-detecting layer, in which glucose oxidase was immobilized on cross-linked polyacrylamide. The second layer functioned as an interface between the insulin supply and the detecting film. Made out of N, N-diethyl aminoethyl methacrylate, and 2-hydroxypropyl methacrylate (DEA-HPMA), it shaped the obstruction film $[48,49]$.

\section{Externally regulated pulsatile drug delivery \\ Electro responsive pulsatile release}

An electric field as an external stimulus has a benefits, for example, the accessibility of gear that permits exact control concerning the extent of the flow, term of electric heartbeats, the stretch between beats, and so forth electrically responsive delivery system is set up from polyelectrolytes and is in this manner $\mathrm{pH}$-responsive just as electro responsive. Affected by the electric field, electro responsive hydrogels by and large de swell, expand, or disintegrate. Poly (2-acrylamide-2-methyl propane sulfonic corrosive co-butyl methacrylate) [P(AMPS-co-BMA)] hydrogels were utilized for electric boosts instigated drug conveyance frameworks [50]. Kwon et al. misused cross-connected poly(2-acrylamide-2-methyl propane sulfonic corrosive co-butyl methacrylate) (P(AMPS-co-BMA)) hydrogels for electric improvements actuated medication delivery. The systems of medication discharge incorporate removal of medication from the gel as the liquid eliminate syneresis, drug dissemination along a fixation slope and electrophoresis of a charged medication toward an oppositely charged terminal, and the arrival of the captured drug as the gel complex dissolve concerning the size of the flow, span of electric heartbeats, the stretch between beats, and so forth electrically responsive delivery system is set up from polyelectrolytes and is consequently pH-responsive just as electro responsive. Affected by an electric field, electro responsive hydrogels by and large de swell, expand, or dissolve. Poly (2-acrylamide-2-methyl propane sulfonic corrosive co-butyl methacrylate) P(AMPS-co-BMA) hydrogels were utilized for electric upgrades incited drug delivery system $[51,52]$.

\section{Ultrasonically stimulated}

Ultrasound is for the most part utilized as an enhancer for the improvement of medication pervasion through a natural hindrance, such as skin, lungs, intestinal wall, and veins. A few reports are depicting the impact of ultrasound on controlled medication conveyance. Kost and associates portrayed an ultrasound-upgraded polymer. Miyazaki et al. utilized ultrasound to accomplish up to a 27-overlay expansion in the arrival of 5-fluorouracil from an ethylene and vinyl acetic acid derivation (EVAc) lattice. Expanding the strength of the ultrasound brought about a corresponding expansion in the measure of 5-fluorouracil delivered [53].

\section{Magnetically induced pulsatile release}

The utilization of an oscillating to regulate the medication conveyance from a polymer network was one of the primary approaches explored 
to build up a remotely controlled medication conveyance framework. Attractive transporters get a reaction to an attractive field from consolidated materials, such as magnetite, iron, nickel, cobalt, and so on. For biomedical applications, attractive transporters should be water-based, biocompatible, non-harmful, and non-immunogenic. The unthinking methodology behind the technique depends on hindering the development of oral medications in the GI framework through attractive fascination. This is conceivable by filling an extra attractive segment into cases or tablets. The speed of movement through the stomach and intestinal tracts would then be able to be eased back down at explicit situations by an outer magnet, in this manner changing the circumstance and additionally a degree of medication retention into the stomach or intestinal tracts $[54,55]$.

\section{MARKETED TECHNOLOGIES OF PULSATILE DRUG DELIVERY}

Diverse advertised advances have been produced for pulsatile drug delivery, such as Pulsincap ${ }^{\mathrm{TM}}$, Diffucap ${ }^{\circledast}$, three-dimensional printing ${ }^{\circledR}$ (3DP), chronotherapeutic oral drug absorption system (CODAS ${ }^{\circledR}$ ), OROS $^{\circledR}$, intestinal defensive medication assimilation system (IPDAS ${ }^{\circledR}$ ), GEOCLOCK $^{\circledR}$, Ritalina ${ }^{\circledR}$, Uniphy ${ }^{\circledR}$, and Opana ${ }^{\circledR}$ ER [56-58]. Some of them are examined underneath:

\section{Pulsincap $^{\text {TM }}$ technology}

Pulsincap was created by R.R. Scherer International Corporation (Michigan). This gadget comprises a non-breaking down half case body fixed at the open end with a hydrogel plug that is covered by a water-dissolvable cap. The entire unit is covered with an enteric polymer to keep away from the issue of variable gastric emptying. At the point when this capsule interacts with the dissolution fluid, it swells, and after a lag time, the attachment propels itself outside the case and quickly delivers the medication. Another definition approach was as bead or granule with a four-layered round structure, which comprises a core, a medication swelling agent (e.g., sodium starch glycolate or carboxymethyl cellulose sodium), and an external film of water-insoluble polymer (e.g., ethylcellulose and Eudragit ${ }^{\circledR}$ RL). The entrance of GI liquids through the external film causes the extension of the swelling agent. The subsequent pressure because of expanding power prompts the obliteration of the film and ensuring fast medication discharge. Polymers utilized for planning the hydrogel plug were different thickness evaluations of hydroxyl propyl methyl cellulose, polymethyl methacrylates, polyvinyl acetic acid derivation, and polyethylene oxide. Another new methodology was entericcovered, coordinated delivery, and press-covered tablets (ETP tablets). These tablets were created by coated enteric polymer on coordinated delivered, press-coated tablets made out of an external shell of hydroxyl propyl cellulose and core tablets containing diltiazem hydrochloride as a model medication [59-61].

Patel and Patel built up and altered the pulsincap gadget containing diclofenac sodium to focus on the medication in the colon. This is a site-specific and time-subordinate detailing; that is, by regulating the plan at sleep time, indications that are capable promptly in the first part of the day are kept away from. This helpful impact is delayed by ceaselessly delivering the prescription over an all-inclusive period in the wake of overseeing a solitary portion. The target of the investigation was to investigate the time-and $\mathrm{pH}$-dependent controlled drug delivery of Diclofenac Sodium utilizing the pulsincap system [62].

\section{DIFFUCAPS $^{\circledR}$ technology}

Varieties in pH all through the GIT influence the solubility and absorption of specific medications. This $\mathrm{pH}$ reliance can cause an issue, especially when building up a supported or controlled delivery formula. Carvedilol and dipyridamole are drugs that are solvent in the acidic states of the stomach yet are insoluble in the impartial/marginally basic states of the digestive tract, where the ingestion of the dynamic medication is ideal. of specific concern are feeble, fundamental medication intensifies that are insoluble at a pH more prominent than five. Eurand's Diffucaps ${ }^{\circledR}$ innovation works with the turn of events and commercialization of novel, controlled-discharge conveyance frameworks for on more than one occasion every day dosing of single medications or medication mixes that show outrageous $\mathrm{pH}$-subordinate dissolvability profiles and additionally are ineffectively solvent in physiological liquids. This restrictive innovation has been grown explicitly for powerless, fundamental medications and includes the consolidation of a chemically adequate natural corrosive or a crystallization-repressing polymer onto dormant centers and covering the medication layered dabs with exclusive useful polymers. Details utilizing a corrosive center guarantee that an acidic climate encompasses the medication consistently, subsequently delivering a dissolvable medication in an in vivo climate where it would some way or another be insoluble [63].

Diffucaps $^{\circledR}$ is a multiparticulate beads system involved various layers of the medication, excipients, and release controlling polymers. The beads contain a layer of organic acid or alkaline buffer to control the solubility of a drug by creating an optimal $\mathrm{pH}$ microenvironment for drugs that display helpless dissolvability in intestinal $\mathrm{pH}$, in conditions with $\mathrm{pH}$ more prominent than 8.0 or in physiological liquids. Diffucaps ${ }^{\circledR}$ dabs are $<1.5 \mathrm{~mm}$ in measurement and can be filled into containers or compacted into orally deteriorating tablets. Plus, for patients who experience trouble in gulping tablets or cases, Diffucaps ${ }^{\circledR}$ items are created in containers that permit the cases to be opened and the substance utilized as a sprinkle on food sources, giving an adaptable measurement structure. The adaptability of the Diffucaps ${ }^{\circledR}$ framework takes into consideration simple change of the delivery profile and dosing solidarity to accomplish focused in vivo results. This adaptability improves on portion going investigations for drug advancement accomplices associated with clinical testing because the beads can be exemplified independently to make separate examination arms [64].

Eurand's Diffucaps ${ }^{\circledR}$ innovation is utilized in a few as of now advertised items and novel items in clinical turn of events. Diffucaps ${ }^{\circledR}$ multiparticulate globule framework empowered the improvement of a plan with an underlying arrival of the medication for the fast beginning of the activity to keep up predictable plasma levels for the day. AMRIX is accessible in two portion relative qualities, 15 and $30 \mathrm{mg}$ containers. This delineates a benefit of the Diffucaps ${ }^{\circledR}$ innovation various item qualities can be promptly evolved by utilizing contrasting measures of medication layered dots contained in the last case dose structure. Diffucaps ${ }^{\circledR}$ innovation made a deferred discharge case that accomplishes top plasma levels in the AMRIX when patient danger is most noteworthy and proceeded with upkeep for the day.

Benefits of this multiparticulate framework are its reasonableness for drugs displaying helpless dissolvability in the lower intestinal $\mathrm{pH}$, in conditions with a pH above 8.0 or in physiological liquids, where it can give measurement strength adaptability and the necessary PK profile, give ideal delivery profiles for single medications and medication mixes and can limit food impact. The Diffucaps ${ }^{\circledR}$ drug discharge framework can likewise be utilized in mix with other Eurand innovations to upgrade drug dissolvability in the GIT $[1,65,66]$.

\section{DP ${ }^{\circledR}$}

3DP is a novel strong freestyle creation innovation that has been applied to the manufacture of complex drug gadgets, or 3DP is fast prototyping (RP) innovation. Prototyping includes developing explicit layers that utilization powder handling and fluid restricting materials. Reports in the writing have featured the numerous benefits of the 3DP framework over different cycles in upgrading drug applications; these remember new techniques for the plan, improvement, production, and commercialization of different kinds of strong measurement structures. For instance, 3DP innovation is adaptable in that it very well may be utilized in applications connected to straight medication conveyance frameworks, colon-focused on conveyance frameworks, oral quick crumbling delivery system, drifting conveyance frameworks, timecontrolled, and beat discharge delivery system just as dose structures with multiphase delivery properties and implantable DDS. Likewise, 3DP can give answers for settling challenges identifying with the conveyance of ineffectively water-dissolvable medications, peptides, 
and proteins, profoundly harmful and strong medications, and controlled arrival of multi drugs in a solitary measurement structure.

Because of its adaptable and exceptionally reproducible assembling measure, 3DP has a few benefits over customary packing and other RP innovations in manufacturing strong DDS. This empowers 3DP to be additionally produced for use in pharmaceutics applications. Be that as it may, a few issues limit the further uses of the framework, for example, the choice of reasonable excipients and the drug store specialized properties of 3DP items. Further improvements are thusly expected to defeat these issues so 3DP frameworks can be effectively joined with regular pharmaceutics [67].

Limits of the innovation as identifying with drugs have been tended to, and model measurement structures have been created. The goal of the 3DP tablets was found to rely upon molecule size and fluid movement during printing and drying. The surface completion of 3DP tablets was improved by uniaxial squeezing. Movement hindering added substances was successful in restricting vehicles. Both fluid and ethanol-based arrangements showed an abatement in movement on the request for $20 \%$ when suitable powder bed added substances were presented. The relocation was additionally diminished by preprinting obstructions to limit optional printed drug arrangements. Low measurement structures were created with just $2.3 \mathrm{ng}$. Lower doses are an endless supply of the underlying medication arrangement. Printing structures with high doses are restricted by powder void volume, filling proficiency, and medication dissolvability limits.

Complex oral measurement structures were manufactured with 3DP to show slacked discharge, broadened discharge, two-fold delivery, and zero-request discharge. Delivery properties, for example, slack time and delivery rate, were controlled by changing the printing boundaries. Double delivery and zero-request discharge structures were manufactured utilizing a surface debasement/disintegration framework dependent on HPMC, lactose, and Eudragit RL100. Disintegration rate constants were utilized to display discharge from tablets with non-uniform medication appropriations. Diclofenac and chlorpheniramine double delivery tablets were planned with threedrug districts, and disintegration of the tablets followed the model intently, showing two onsets. Two kinds of zero-request tablets were created and manufactured by 3DP. These contained medication focus inclinations intended to supplement the volumetric non-consistency of dissolving shells. Three definitions showed consistent arrival of diclofenac sodium more than $1-7 \mathrm{~h}(9.6 \mathrm{mg} / \mathrm{h}), 1-15 \mathrm{~h}(6.8 \mathrm{mg} / \mathrm{h})$, and $1-36 \mathrm{~h}(2.5 \mathrm{mg} / \mathrm{h})[68,69]$.

\section{CODAS $^{\circledR}$}

In specific cases, the quick arrival of medications is bothersome. A deferral of medication activity might be needed for an assortment of reasons. Chronotherapy is an illustration of when medication delivery might be modified to happen after a delayed stretch after organization. Energy Drug Technology created CODAS ${ }^{\circledR}$ innovation to accomplish this drawn-out stretch. The numerous benefits of the CODAS ${ }^{\circledR}$ innovation incorporate a delivery profile intended to commend circadian example, controlled beginning, an all-inclusive delivery conveyance framework, pace of delivery autonomous of pH, stance, and food, "sprinkle" dosing by opening the case and sprinkling the substance on food, decrease in the viable day by day portion and medication openness, GI plot focusing for neighbor-hood impact, and diminished foundational openness to accomplish an objective profile $[70,71]$.

Verelan $^{\circledR}$ PM utilizes the restrictive CODAS $^{\mathrm{TM}}$ innovation, which is intended for sleep time dosing, consolidating a $4-5 \mathrm{~h}$ delay in drug conveyance. The controlled-beginning delivery system brings about a most extreme plasma focus (Cmax) of verapamil in the first part of the day hours. These pellet-filled containers accommodate broadened arrival of the medication in the GI lot. The Verelan ${ }^{\circledR}$ PM plan has been intended to start the arrival of verapamil 4-5 $\mathrm{h}$ after ingestion. This postponement is presented by the degree of nonenteric delivery controlling polymer applied to tranquilize stacked globules. The delivery controlling polymer is a blend of watersolvent and water-insoluble polymers. As water from the GI lot comes into contact with the polymer-covered globules, the watersolvent polymer gradually breaks up, and the medication diffuses through the subsequent pores in the covering. The water-insoluble polymer keeps on going about as an obstruction, keeping up the controlled arrival of the medication. The pace of delivery is free of $\mathrm{pH}$, stance, and food. Multiparticulate systems, such as Verelan ${ }^{\circledR} \mathrm{PM}$, are free of GI motility [72].

\section{OROS $^{\circledR}$ technology}

OROS delivery systems were embraced for ineffectively waterdissolvable polymers. The push-pull framework is contained a bilayer or trilayer tablet core comprising of one push layer and at least one medication layer. The medication layer contains ineffectively dissolvable medications, osmotic specialists, and a suspending specialist. The push layer contains in addition to other things, an osmotic specialist and water-swellable polymers. A semipermeable film encompasses the tablet core. An assortment of OROS $^{\circledR}$ frameworks (ALZA Corp.) has been created: Procardia $\mathrm{XL}^{\circledR}$, Ditropan $\mathrm{XL}^{\circledR}$, and Concerta ${ }^{\circledR}$ are prominent models. The as of late created L-OROS ${ }^{\circledast}$ SOFTCAP $^{\mathrm{TM}}$ conveyance framework joins the highlights of a controlled-delivery and bioavailability-improved delivery system to upgrade consistency and restorative impact $[73,74]$.

L-OROS $^{T M}$ innovation was created by Alza to beat the medication solvency issue. These details incorporate self-emulsifying fluid transporter plans (SEF) that permit medication to be all the more promptly retained through the GI layer and circulation system. The SEF in L-OROS frameworks comprises medications in non-fluid transporters planned to give either an answer or a nanosuspension. As a medication in an arrangement is delivered in the GI parcel, it frames exceptionally little drops $(<100 \mathrm{~nm})$, expanding the solvency of the medication, along these lines improving bioavailability. As the medication in a nanosuspension is delivered, the medication nanoparticles are scattered, and accumulation is forestalled [75-77].

\section{IPDAS $^{\circledR}$}

The IPDAS is another oral medication conveyance approach that applies to GI aggravation drugs, including the nonsteroidal mitigating drug (NSAID) class. IPDAS ${ }^{\circledR}$ conveyance framework can likewise be utilized to present the benefits of multiparticulate innovation in a tablet dose structure. The IPDAS ${ }^{\circledR}$ innovation is made out of various high-thickness, controlled-discharge dots, which are compacted into a tablet structure. When an IPDAS ${ }^{\circledR}$ tablet is ingested, it deteriorates and scatters globules containing a medication in the stomach, which hence passes into the duodenum and along with the GI parcel in a controlled and continuous way, autonomous of the taking care of the state. The arrival of dynamic fixing is constrained by the polymer system used to cover the dots or potentially the miniature lattice of polymer/ dynamic fixing shaped in the expelled/spheronized multiparticulates. The intestinal insurance of IPDAS $^{\circledR}$ innovation is characteristic of the multiparticulate idea of the definition, which guarantees a wide scattering of aggravation drugs all through the GI lot. IPDAS ${ }^{\circledR}$ was at first planned as a feature of the advancement interaction for Elan Drug Technologies' exclusive naproxen definition, Naprelan ${ }^{\circledR}$ [66]. Even though naproxen, as the free corrosive or the sodium salt has pharmacokinetic qualities that are predictable with once-day-by-day dosing, the GI aggravation and ulcerogenic potential are related with a huge bolus portion of naproxen blocks safe utilization of a prompt delivery structure. In addition, the ideal pharmacodynamic action of a once-day-by-day measurement type of naproxen requires quickly accessible naproxen for a brief beginning of pain-relieving movement just as a delayed period of retention to give $24 \mathrm{~h}$ pain relieving/ calming action. The goal was to build up a once-day-by-day controlleddischarge framework with a quick beginning of activity and diminished gastric irritancy. The goal was accomplished in Naprelan ${ }^{\circledR}$; it has a 
demonstrated beginning of relief from discomfort inside 30 min that endures up to $24 \mathrm{~h}$ and is well-tolerated. The numerous benefits of the IPDAS ${ }^{\circledR}$ innovation incorporate high-thickness multiparticulate definition, GI security for all the more locally aggravation drugs (e.g., NSAIDs), benefits of multiparticulate in a tablet structure, and quick beginning whenever required $[78,79]$.

\section{GeoClock $^{\circledR}$}

SkyePharma built up another oral drug delivery innovation, GeoClock ${ }^{\circledR}$, as chronotherapy-centered press-covered tablets. GeoClock ${ }^{\circledR}$ tablets have a functioning medication inside an external tablet layer comprising a combination of hydrophobic wax and weak material to get a $\mathrm{pH}$-free slack time before center medication conveyance at a foreordained delivery rate. This dry covering approach is intended to permit the coordinated arrival of both lethargic delivery and prompt delivery dynamic centers by delivering the inward tablet first, at which point, the encompassing external shell step by step breaks down. Notwithstanding controlled delivery, the GeoClock $^{\circledR}$ innovation likewise has applications for the improved arrival of colonic medication conveyance just as for numerous heartbeat drug conveyance to convey dosages of medication at explicit occasions for the day. Utilizing SkyePharma's exclusive GeoClock ${ }^{\mathrm{TM}}$ innovation, Lodotra ${ }^{\mathrm{TM}}$ appeared as an uncommonly formed tablet, which, once ingested, did not deliver the dynamic fixing, prednisone, until around $4 \mathrm{~h}$ after the fact. Lodotra $^{\mathrm{TM}}$ has been planned so the greatest plasma levels arrive $6 \mathrm{~h}$ after consumption. This empowers a patient to swallow the tablet at 10 p.m. before resting, with the portion of prednisone not being delivered until 2 a.m. what's more, arriving at greatest plasma levels at 4 a.m., which is viewed as the ideal planning to soothe the solidness and torment on strolling. This evening time discharge detailing is particularly fit to the treatment of early morning firmness, which is related to rheumatoid joint pain brought about by the checked arrival of fiery cytokines, including interleukin- 6 in the early hours of the morning [80]

\section{Uniphyl ${ }^{\circledR}$}

Uniphyl (theophylline, anhydrous) tablets in a controlled-release system permit a $24 \mathrm{~h}$ dosing span for patients. Uniphyl controlled in the fed state is assimilated after oral organization.

\section{PULSYS $^{\text {TM }}$}

MiddleBrook Pharmaceuticals, Inc., has built up a delivery innovation called PULSES, which empowers pulsatile conveyance or conveyance in quick explosions of specific medications. The innovation gives the drawn-out delivery and retention of a medication. The organization's PULSES item MOXATAG (amoxicillin broadened discharge) tablets, $775 \mathrm{mg}$ are utilized for the treatment of pharyngitis/tonsillitis optional to Streptococcus pyogenes, ordinarily known as strep throat, for grownups and pediatric patient's age 12 and more seasoned. MOXATAG's once-day-by-day expanded delivery tablet comprises three segments: One quick delivery and two postponed discharge segments. The three segments are consolidated in a particular proportion utilizing its PULSES innovation to draw out the arrival of amoxicillin from MOXATAG contrasted and quick delivery amoxicillin $[81,82]$.

\section{Cover-HS}

Cover-HS is the first once-day-by-day plan of an antihypertensive/ against anginal specialist that utilizes a high-level tablet covering and a novel drug delivery system to impersonate the body's regular $24 \mathrm{~h}$ circadian varieties in pulse and pulse. This novel conveyance innovation, called COER-24 $4^{\mathrm{TM}}$ (Controlled-Onset-Extended-Release), was created related to Alza Corp. Cover-HS is the lone controlleddischarge verapamil detailing that is at present affirmed with a sign for the administration of both (hypertension) and angina pectoris (chest torment). Accessible in both $180 \mathrm{mg}$ and $240 \mathrm{mg}$ tablets, Covera-HS is intended for oral dosing at sleep time. The pinnacle centralization of Covera-HS is conveyed in the early waking hours when circulatory strain and pulse are increases at their most noteworthy rate. There is insignificant medication conveyance during rest when pulse and pulse are at their physiologic most minimal [73].
Time multiple action delivery systems (TMDS)

This system controls discharge rates for numerous fixings inside a solitary tablet in a customized way. TMDS innovation considers the arrival of more than one dynamic fixing in a solitary tablet definition to be delivered in various profiles over a long period.

\section{Geomatrix $^{\mathrm{TM}}$}

Another delivery gadget, as a multi-facet tablet, has as of late been proposed for steady medication discharge dependent on Geomatrix ${ }^{\circledR}$ Technology. It comprises a hydrophilic grid center, containing the dynamic fixing and a couple of impermeable or semi-penetrable polymeric coatings (films or compacted boundaries) applied on one of the two bases of the center. The Geomatrix ${ }^{T M}$ innovation is applied to accomplish tweaked levels of controlled arrival of explicit medications and can accomplish concurrent arrival of two unique medications and various rates from a solitary tablet. The presence of the coatings alters the hydration/expanding pace of the center and decreases the surface region accessible for drug discharge. These halfway coatings give a balance of the medication disintegration profile; that is, they decrease the delivery rate from the gadget and shift the run-of-themill time-subordinate delivery rate toward consistent medication discharge. To accomplish controlled delivery, a complex tablet was developed utilizing two essential segments, hydrophilic polymers, for example, HPMC, and surface-controlling obstructions. The dynamic stacked center surface that is accessible for drug discharge when presented to the liquid is constrained by obstruction layers. Utilizing this novel innovation, SkyePharma has created Lodotra ${ }^{\mathrm{TM}}$, containing a rheumatoid joint pain drug. Lodotra ${ }^{\mathrm{TM}}$ conveys the dynamic drug fixing at the most appropriate season of day to treat the illness. Benefits of the Geomatrix $^{\mathrm{TM}}$ innovation are their capacity to be effortlessly consolidated into the creation line, to be produced by promptly accessible gear, reproducibility, adequacy, the flexibility of delivery control systems, controlled arrival of ineffectively solvent medications, coordinated arrival of medications, bi-phasic arrival of medications, the arrival of at least two medications at various rates, the beat arrival of medications, and well-being of utilization [66,80,84-87]

\section{OSDRC technology}

The regular dry-covered tablet (DC) strategy requires center tablet arrangement previously, and hence, the muddled methodology of the ordinary DC technique expands the assembling cost and the possibility of disappointment, which may prompt an ascent in center tablet supply. To tackle this issue OSDRC-innovation (one-venture dry-covered tablet framework, and OSDRC-system) was built up that utilizes a two-fold design punch (focus punch and external punch) taking into account dry-covered tablets to be collected in a solitary run. The assembling interaction comprises three stages: Base layer (the first external layer) pressure, center pressure, and entire tablet pressure, which incorporates the upper layer and side layer (the second external layer). Since the tablets are created in a solitary advance while the punches make one revolution on a turntable, there could be not, at this point any requirement for a different stage to convey the center [87-90].

\section{Diffutab $^{\circledR}$}

Diffused innovation empowers altered delivery profiles and district explicit conveyance. The Diffutab innovation fuses a mix of waxes and hydrophilic polymers that control drug discharge through dissemination and disintegration of a grid tablet. Diffutabs are especially valuable for high-portion items and medications that require supported delivery as well as once-a-day dosing. Eurand applied this innovation to both dissolvable and insoluble items. The benefits of Diffutabs are high medication stacking, supporting supported delivery, and once-a-day dosing, as lattice tablets use a blend of water-solvent particles and dynamic medications $[1,9]$.

\section{Orbexa $^{\circledR}$}

Orbexa innovation is a multiparticulate framework that empowers high medication stacking and is reasonable for items that require granulation. Eurand's Orbexa innovation produces dots of controlled 
Table 1: Marketed technologies of Pulsatile drug delivery [22,93-95]

\begin{tabular}{|c|c|c|c|c|}
\hline Technology & Mechanism & $\begin{array}{l}\text { Proprietary name } \\
\text { and dosage form }\end{array}$ & $\begin{array}{l}\text { Active pharmaceutical } \\
\text { ingredients }\end{array}$ & Disease \\
\hline PULSYS $^{\mathrm{TM}}$ & Rupturable system & Pulsincap $^{\mathrm{TM}}$ & Dofetilide & Antiarrhythmic \\
\hline $\begin{array}{l}\text { Physicochemical } \\
\text { modification of API }\end{array}$ & Tablet & Pepcid $^{\circledR}$ & Famotidine & ulcer \\
\hline OROS & Osmotic mechanism & $\begin{array}{l}\text { Covera-H5 } \\
\text { XL } \\
\text { Tablet }\end{array}$ & $\begin{array}{l}\text { Verapamil } \\
\text { HCL }\end{array}$ & Hypertension \\
\hline DIFFUCAPS* & Multiparticulate system & $\begin{array}{l}\text { Innopran XL, } \\
\text { Tablet }\end{array}$ & $\begin{array}{l}\text { Verapamil } \\
\text { HCL, } \\
\text { Propranolol }\end{array}$ & Hypertension \\
\hline Pulsincap $^{\text {TM }}$ & Rupturable system & Pulsincap $^{\mathrm{TM}}$ & Dofetilide & Hypertension \\
\hline CODAS $^{\circledR}$ & Extended release capsule & Verelan ${ }^{\circledR} \mathrm{PM}$ & Verapamil HCl & Hypertension \\
\hline TIMERx $^{\circledR}$ & Erodible/ER Tablets & OPANA $^{\circledR S}$ & Oxymorphone & $\begin{array}{l}\text { Pain } \\
\text { management }\end{array}$ \\
\hline
\end{tabular}

size and thickness utilizing granulation spheronization and expulsion strategies. These dots give higher medication fixation than different frameworks, can be covered with practical polymer layers for extra delivery rate control, are adaptable, and are appropriate for use with touchy materials, such as compounds. Eurand's Orbexa innovation can be utilized for gastric insurance, postponed discharge, supported delivery, site-explicit delivery, pulsatile delivery, complex delivery design, the partition of inconsistent, and blend items. Orbexa dots can be filled into cases or single-portion sachets $[78,91]$.

\section{Minitabs $^{\circledR}$}

Eurand's Minicabs are small $(2 \mathrm{~mm} \times 2 \mathrm{~mm})$ tube-shaped tablets covered with a useful film to control the pace of medication discharge. Eurand Minitabs contain gel-shaping excipients that control the medication discharge rate. Extra layers might be added to additional control the delivery rate. The tablets are filled into cases, permitting a mix of numerous medications or potentially different delivery profiles in a similar measurement structure. The Eurand Minitabs can be planned as lattice tablets before additional covering. Eurand Minicabs can likewise be utilized as a sprinkle on food. Eurand Minitabs joins the effortlessness of tablet detailing with the refinement of multiparticulate frameworks, appropriate for high medication stacking, and can be utilized as a sprinkle for pediatric and geriatric patients who experience issues gulping tablets [78,92] (Table 1 ).

\section{CONCLUSION}

The circadian rhythm of the body is an important concept for understanding the optimum need for the drug in the body. There is a constant need for new delivery systems that can provide increased therapeutic benefits to the patients. Pulsatile drug delivery is one such system that, by delivering drug at the right time, right place, and in right amounts, holds good promises of benefit to the patients suffering from chronic problems such as arthritis, ulcer, asthma, and hypertension. Thus, designing proper pulsatile drug delivery will enhance the patient compliance, optimum drug delivery to the target site, and minimizes the undesired effects.

\section{ACKNOWLEDGMENT}

The authors acknowledge The Oxford College of Pharmacy, Bengaluru, for providing the necessary internet and library facilities and support to complete the work.

\section{AUTHORS CONTRIBUTIONS}

All the authors have contributed equally.

\section{CONFLICTS OF INTERESTS}

The authors declare that they have no conflicts of interest.

\section{REFERENCES}

1. Jain D, Raturi R, Jain V, Bansal P, Singh R. Recent technologies in pulsatile drug delivery systems. Biomatter 2011;1:57-65.

2. Patel VP, Soniwala M. Pulsatile drug delivery system for treatment of various inflammatory disorders. Int J Drug Dev 2012;3:67-87.

3. Mohd AH, Raghavendra RN. Novel technologies in formulations. World J Pharm Res 2012;1:1-17.

4. Bussemer T, Peppas NA, Bodmeier R. Evaluation of the swelling, hydration, and rupturing properties of the swelling layer of a rupturable pulsatile drug delivery system. Eur J Pharm Biopharm 2003;56:261-70.

5. Maroni A, Zema L, Loreti G, Palugan L, Gazzaniga A. Film coatings: A review. Oral pulsatile release. Int J Pharm 2013;457:362-71.

6. El-Maradny HA. Modulation of a pulsatile release drug delivery system using different swellable/rupturable materials. Drug Deliv 2007; 14:539-46

7. Ghimire M, McInnes FJ, Watson DG, Mullen AB, Stevens HN. In-vitro/in-vivo correlation of pulsatile drug release from press-coated tablet formulations. Eur J Pharm Biopharm 2007;67:515-23.

8. Pasham S, Venkatesh DP, Sujit N. Pulsatile drug delivery system: An overview. A formulation approach for the treatment of diseases. Int J Curr Pharm Res 2020;14:16-21.

9. Bussemer T, Otto I, Bodmeier R. Pulsatile drug-delivery systems. Crit Rev Ther Drug Carrier Syst 2001;18:433-58.

10. Santini JT, Scheidt RA, Cima R, Langer MJ, Angew R. Chem Int Ed 2000;39:2397-407.

11. Prescott JH, Lipka S, Baldwin S, Sheppard NF, Maloney JM, Coppeta J, et al. Chronic, programmed polypeptide delivery from an implanted, multi-reservoir microchip device. Nat Biotechnol 2006;24:437-8.

12. Shidhaye S, Lotlikar V, Ghule A, Phutane P, Kadam V. Pulsatile delivery systems: An approach for chronotherapeutic diseases. Sys Rev Pharm 2010;1:5-61.

13. Richards Grayson AC, Choi IS, Tyler BM, Wang PP, Brem H, Cima MJ, et al. Multi-pulse drug delivery from a resorbable polymeric microchip device. Nat Mater 2003;2:767-72.

14. Santini JT, Cima MJ, Langer R. A controlled-release microchip. Nature 1999;397:335-8.

15. Ritschel WA, Forusz H. Chronopharmacology: A review of drugs studied. Methods and findings in experimental and clinical pharmacology. EMBO J 1994;16:57-75.

16. Reddy JR, Jyothsna MV, Saleem TM, Chetty CM. Review on: Pulsatile drug delivery systems. J Pharm Sci Res 2009;1:109-15.

17. Yang SY, Yang JA, Kim ES, Jeon G, Oh EJ, Choi KY, et al. Singlefile diffusion of protein drugs through cylindrical nanochannels. ACS Nano 2010;4:3817-22.

18. Jha N, Bapat S. Chronobiology and chronotherapeutics. KUMJ 2004;2:384-8.

19. Bruguerolle B, Lemmer B. Recent advances in chronopharmacokinetics: A review. Methodological problems. Life Sci 1993;52:1809-24.

20. Sarkhejiya NA, Praful DB. Newer insights into pulsatile drug delivery systems. WJPS 2017;5:134-50.

21. Youan BB. Chronopharmaceutics: Gimmick or clinically relevant approach to drug delivery? J Control Release 2004;98:337-53.

22. Chhabra VS, Shrikant KT, Walde SR, Abhay M. The essentials of 
chronopharmacotherapeutics. Int J Pharm Pharm Sci 2012;4:1-8.

23. Rompicharla B, Prabha KS, Tabasum M. A comprehensive review of pulsatile drug delivery system. Int Res J Pharm 2012;3:106-8.

24. Patil ND, Bari MM, Barhate SD. A review on novel approach pulsatile drug delivery system. Int J Pharm Sci Rev Res 2013;21:209-22.

25. Pandit V, Kumar A, Ashawat MS, Verma CP, Kumar P. Recent advancement and technological aspects of pulsatile drug delivery system-a laconic review. Curr Drug Targets 2017;18:1191-203.

26. Rathod S. Colon targeted pulsatile drug delivery: A review. Pharm net 2007;5:1-1.

27. Survase S, Kumar N. Pulsatile drug delivery: Current scenario. CRIPS 2007;8:27-33

28. Hermida RC, Ayala DE, Portaluppi F. Circadian variation of blood pressure: The basis for the chronotherapy of hypertension. Adv Drug Deliv Rev 2007;59:904-22.

29. Janugade BU, Patil SS, Patil SV, Lade PD. Pulsatile drug delivery system for chronopharmacological disorders: An overview. J Pharm Res 2009;2:132-43.

30. Desai TR, Matholiya CR, Patel VP, Chhayani RB. Pulsatile drug delivery system: A review. Pharma Tutor 2015;2:1-30

31. Sarasija S, Hota A. Colon-specific drug delivery systems. Indian J Pharm Sci 2002;62:1-8.

32. Kinget R, Kalala W, Vervoort L, Van den Mooter G. Colonic drug targeting. J Drug Target 1998;6:129-49.

33. Krögel I, Bodmeier R. Pulsatile drug release from an insoluble capsule body controlled by an erodible plug. Pharm Res 1998;15:474-81.

34. Wu F, Zhang ZR, He WL, Zhang Y. Preparation and in vitro release of tetramethylpyrazine phosphate pulsincap capsule controlled by an erodible plug. Acta Pharm Sin B 2002;37:733-8.

35. Crison JR, Siersma PR, Amidon GL. A novel programmable oral release technology: For delivering drugs. Bioact Mater 1996;23:51-2.

36. Pollock Dove C, Dong L, Wong PA. New system to deliver a delayed bolus of liquid drug formulation. Bioact Mater 2001;28:6033.

37. Balaban SM, Pike JB, Smith JP, Baile CA. Osmotically driven delivery devices with pulsatile effect. U S Patent 5 1993;209:746-52.

38. Magruder PR, Barclay B, Wong PS, Theeuwes F. A composition comprising a therapeutic agent and a modulating agent. U S Patent 4 1989;851:229-310

39. Maroni A, Sangalli ME, Cerea M, Busetti C, Giordano F, Gazzaniga A. Low viscosity HPMC coating of soft and hard gelatin capsules for delayed and colonic release: Preliminary investigations on process parameters and in vitro release performances. Bio Act Mater 1999;26:887-8.

40. Patel GN, Patel GC, Patel RB, Patel SS, Patel JK. Oral colon-specific drug delivery. Drug Deliv Technol 2006;6:62-71.

41. Gazzaniga A, Colombo P, Manna A, Conte U. A new ibuprofen pulsed release oral dosage form. Drug Dev Ind Pharm 1989;15:2583-96.

42. Krogel I, Bodmeier R. Floating or pulsatile drug delivery systems based on coated effervescent cores. Int J Pharm 1999;187:175-84.

43. Ueda S, Yamaguchi H, Kotani M, Kimura S, Tokunaga Y, Kageyama AH, et al. development of a novel drug release system, time-controlled explosion system. Chem Pharm Bull 1994;42:359-63.

44. Beckert TE, Pogarell K, Hack I, Petereit HU. Pulsed drug release with film coatings of Eudragit and Mac226; RS 30D. Proc Int Symp Controlled Release Bioact 1999;26:533-34.

45. Dalvadia H, Patel JK. Chronpharmaceutics, pulsatile drug delivery system as the current trend. Asian J Pharm Sci 2010;5:204-30.

46. Oh KS, Han SK, Choi YW, Lee JH, Lee JY, Yuk SH. Hydrogen-bonded polymer gel and its application as a temperature-sensitive drug delivery system. Biomaterials 2004;25:2393-8.

47. Kataoka K, Miyazaki H, Bunya M. synthetic polymer gels responding to external glucose concentration: Their preparation and application to on-off regulation of insulin release. J Am Chem Soc 1998;120:12694-5.

48. Ishihara K, Kobayashi M, Ishimaru N, Shinohara I. Glucoseinduced permeation control of insulin through a complex membrane consisting of immobilized glucose oxidase and a poly (amine). Polym $\mathrm{J}$ 1984;16:625-31.

49. Smith AW. Biofilms and antibiotic therapy: A review. Is there a role for combating bacterial resistance by the use of novel drug delivery systems? Adv Drug Deliv Rev 2005;57:1539-50.

50. Arora S, Ali J, Ahuja A, Baboota S, Qureshi J. Pulsatile drug delivery systems: An approach for controlled drug delivery. Indian J Pharm Sci 2006;68:295-300

51. Yoshida R, Kaneko Y, Sakai K, Okano T, Sakurai Y, Bae YH, et al. Positive thermosensitive pulsatile drug release using negative thermosensitive hydrogels. J Control Release 1994;32:97-102.
52. Wood KC, Zacharia NS, Schmidt DJ, Wrightman SN, Andaya BJ, Hammond PT. Electroactive controlled release thin films. PNAS 2008; $105: 2280-5$.

53. Kost J. Ultrasound for controlled delivery of therapeutics. Clin Mater 1993;13:155-61.

54. Hsieh DS, Langer R, Folkman J. Magnetic modulation of release of macromolecules from polymers. PNAS 1981;78:1863-7.

55. Hoare T, Timko BP, Santamaria J, Goya GF, Irusta S, Lau S, et al. Magnetically triggered nanocomposite membranes: A versatile platform for triggered drug release. Nano Lett 2011;11:1395-400.

56. Parmar RD, Parikh RK, Vidyasagar G, Patel DV, Patel CJ, Patel BD. Pulsatile drug delivery systems. IJPSN 2009;2:605-14.

57. Neurontin. United States: Pfizer Inc.; 2002-2009. Available from: http://www.pfizer.com/files/products/uspi neurontin.pdf.

58. Fukada C, Kohler JC, Boon H, Austin Z, Krahn M. Prescribing gabapentin off label: Perspectives from psychiatry, pain and neurology specialists. CPJ 2012;145:280-84.

59. Hema J, Vaseem AA, Pandit JN, Farogh A. Pulsatile drug delivery system: An overview with special emphasis on losartan and captopril. RJPT 2019;12:3175-88.

60. Fukui E, Miyamura N, Uemura K, Kobayashi M. Preparation of enteric-coated timed-release press-coated tablets and evaluation of their function by in vitro and in vivo tests for colon targeting. Int J Pharm 2000;204:7-15

61. Jose S, Dhanya K, Cinu TA, Litty J, Chacko AJ. Colon targeted drug delivery: Different approaches. J Young Pharm 2009;1:1-13.

62. Patel GC, Patel MM. Developing a modified pulsincap system. Pharm Technol Eur 2009;21:13-9.

63. Steve E. Bioenhancement technologies improve absorption of insoluble drugs in oral dosage forms. Drug Deliv 2007;2:4

64. Parcel PJ, Vishnupad KS, Venkatesh GM. Timed, sustained release systems for propranolol. US Patents 2002;31:1-10.

65. Roy P, Shahiwala A. Multiparticulate formulation approach to pulsatile drug delivery: Current perspectives. J Control Release 2009;134:74-80.

66. Verma RK, Garg S. Current status of drug delivery technologies and future directions. Pharm Technol Eur 2001;25:1-14.

67. Yu DG, Zhu LM, Branford-White CJ, Yang XL. Three-dimensional printing in pharmaceutics: Promises and problems. J Pharm Sci 2008;97:3666-90.

68. Rowe CW, Katstra WE, Palazzolo RD, Giritlioglu B, Teung P, Cima MJ. multimechanism oral dosage forms fabricated by three-dimensional printing. J Control Release 2000;66:11-7.

69. Katstra WE. Fabrication of Complex Oral Drug Delivery Forms by Three Dimensional Printing. Cambridge, Massachusetts: MIT 2001. p. 237-41.

70. Patel R, Patel J. Novel technologies of oral controlled release drug delivery system. Sys Rev Pharm 2010;1:128

71. Panoz DE, Geoghegan EJ. Controlled Absorption Pharmaceutical Composition. United States: US Patent; 1989

72. Sievers EL, Senter PD. Antibody-drug conjugates in cancer therapy. Annu Rev 2013;64:15-29.

73. Lackner TE. Pharmacotherapy of urinary incontinence. J Am Med Dir Assoc 2002;3:16-24.

74. Rappar D. Oral extended-release: Snapshots and benefits. J Drug Deliv Sci Technol 2007;7:30-42.

75. Bhatt AD, Pethe AM. Nanotechnology: A promising drug delivery for poorly water-soluble drugs. J Pharm Res 2010;3:1748-51.

76. Shram M, Romach M, Sellers E, Thipphawong J. Assessing the abuse potential of an oral osmotic-controlled extended-release (OROS) hydromorphone compared to immediate-release hydromorphone. J Pain 2009; 10:S45.

77. Zentner GM, Rork GS, Himmelstein KJ. The controlled porosity osmotic pump. J Control Release 1985;1:269-82.

78. Dey NS, Majumdar S, Rao ME. Multiparticulate drug delivery systems for controlled release. Trop J Pharm Res 2008;7:1067-75.

79. Rewar S, Bansal BK, Singh CJ, Sharma AK, Pareek R. Pulsatile drug delivery system: An overview. JGTPS 2014;5:1943-55.

80. SkyePharma-Drug Delivery Specialists; 2010. Available from: http:// www.skypharma.com

81. Saigal N, Baboota S, Ahuja A, Ali J. Multiple-pulse drug delivery systems: Setting a new paradigm for infectious disease therapy. Expert Opin Drug Deliv 2009;6:441-52

82. Shidhaye S, Dhone A, Budhkar T, Surve C. Technologies in pulsatile drug delivery system. IJAPBC 2012;1:438-45.

83. Conte U, Maggi L, Colombo P, La Manna A. Multi-layered hydrophilic matrices as constant release devices (GeomatrixTM Systems). J Control 
Release 1993;26:39-47.

84. Conte U, Magg L, La Manna A. Compressed barrier layers for constant drug release from swellable matrix tablets. STP Pharma Sci 1994;4:107-13.

85. Conte U, Maggi L. Modulation of the dissolution profiles from Geomatrix ${ }^{\circledR}$ multi-layer matrix tablets containing drugs of different solubility. Biomaterials 1996;17:889-96.

86. Conte U, La Manna A, Colombo P. Tablets with the Controlled Rate Release of Active Substances. United States: US Patent US 5; 1995.

87. Sakurai M, Ozeki Y, Ando M, Okamoto H, Danjo K. Preparation and release profile of colon-targeting drug delivered as novel one-step drycoated tablets. J Pharm Soc Jpn 2007;127:2057-63.

88. Ozeki Y, Danjo K. Development of one-step dry-coated tablet system (OSDRC-System) and the comparison of its compression characteristics with those of conventional dry-coated tablets. J Pharm Sci Technol 2004;64:59-66.

89. Yuichi O, Masaki A, Yukinao W, Kazumi D. Evaluation of novel one- step dry-coated tablets as a platform for delayed-release tablets. J Cont Rele 2004;95:51-60.

90. Ozeki Y, Watanabe Y, Okamoto H, Danjo K. Development of dividable one-step dry-coated tablets (dividable-OSDRC) and their evaluation as a new platform for controlled drug release. Pharm Res 2004;21:1177-83.

91. Shaji J, Chadawar V, Talwalkar P. Multiparticulate drug delivery system. Indian J Pharm Sci 2007:6:21-8.

92. Eurand SP. Corporation Minitab's in Multiparticulate Drug Delivery. ; 2003

93. Lemmer B. Circadian rhythms and drug delivery. J Control Release 1991;16:63-74.

94. Modi MP, Prasanth VV, Mathew ST. pulsatile: A tool for circadian rhythm-a review. JDDT 2012;2:58-65.

95. Kamalpuria N, Dhir S, Jain S. The latest methods and technologies of pulsatile drug delivery system: A review. Int J Pharm Life Sci 2017;8:5446-58 